\title{
Lived Experiences of Tertiary Music Teachers Teaching Musically Challenged Students
}

\author{
Jay P. Mabini \\ jay.mabini@lnu.edu.ph \\ Leyte Normal University, P. Paterno St., Tacloban City, 6500, Philippines
}

\begin{abstract}
This study explored the lived experiences of tertiary music teachers teaching musically challenged students. The phenomenon refers to those who have the difficulty in music aptitude, rhythmic, tonal audiation, and music theory. Seven teachers explored their experiences and best practices in dealing with the phenomenon in which three turning points were identified and these are the ideal teacher, positive regard of the music teachers toward the phenomenon, and the opportunities in dealing with musically challenged students. Key informant interviews were conducted with the participants and were treated qualitatively using thematic analysis. The results confirm that musically challenged students are offshoots of insufficient support from the system, environment, and the student as a whole. The participants' behavior toward the students are rooted and dependent on their personality, skills, and experience in teaching musically challenged students. The results suggest that positive attributes in teaching musically challenged students is inherent in the phenomenon; thus, the experience is meaningful to the teachers. Consequently, the success of the learning process in teaching musically challenged students is clearly dependent on the issues of interest, support, facilities and equipment, and most especially, the quality of teachers handling musically challenged students who innovate strategies and are willing to accommodate the learners; thus, to deal with the phenomenon, music and its related elements should be appraised as a major subject where all components will be truly demonstrated with devoted teachers employing innovative strategies with integration of technology to allow learners to find out the values immanently to make them motivated and confident in the subject.
\end{abstract}

Key Words: Musically challenged students; Rhythmic and tonal audiation; Music aptitude; Tertiary music teachers

\section{Introduction}

Music education is essential in the propagation of music knowledge, skills, and appreciation. The outset of the process may begin in the structured setting of a school or in a more informal manner. According to National Commission for Culture and the Arts (NCCA), the essence of music interpenetrates the daily lives of indigenous culture groups which is beneficial to maintain the rich cultural heritage of the country. Considering this additional subject to the curricula, foundation of knowledge in music is still as important as the pedagogies in teaching to substantiate the effectivity of the instruction. Even Australian music education curriculum starting in primary, and secondary schools as cited by Temmerman (2005), were found in unsatisfactory state based on the examination conducted on their policy and practice of music education because the generalist 
teachers are handling the subject which is a mirror image of the Philippine music education curriculum (Jacinto, 2019). As cited by de Bruin (2018) in Gordon's music learning theory, musically challenged learners are those who have the difficulty in music aptitude, tonal and rhythmic audiation. Likewise, teachers in this subject are given the challenge to teach students to become musically creative which is a complex undertaking. Hence, teachers' approaches create a common ground for students to reconcile the gap between the learners and the subject matter.

A variety of learners can be faced by teachers in a heterogeneous class. Not all students can be expected to be very well versed on the subject matter. According to Gardner's (2011) Multiple Intelligences Theory, everyone has an intelligence which is innate in nature and can be developed over time. This is a fact that is being considered by teachers which is natural in nature to respond to the learners' needs. This creates an idea for educators that activities given must be based on their interest depending on the subject. Understanding the curriculum of State Universities and Colleges (SUC) in the Philippines is essential, in conformity with Commission on Higher Education Memorandum Order No. 20 series of 2013 which implements music under Philippine Popular Culture as part of the general education subjects, CHED CMO No. 80 series of 2017 also known as Policies, standards and guidelines for Bachelor of Physical Education (BPED) which other SUCs including the researcher's research environment are integrating elective music education courses to better capacitate them for the future, and CMO no. 74 series of 2017 also known as Policies, standards and guidelines for Bachelor of Elementary Education which has music courses integrated in its curriculum to enable elementary pre-service teachers to teach music. Anent to this, music teachers of the courses Bachelor of Physical Education and Bachelor of Elementary Education, tend to face the challenge of dealing with students of different capabilities. This makes the classroom diversified with students of various orientations and interests. Specifically, this will require musically challenged students - those who have difficulty in music aptitude, tonal and rhythmic audiation, and music theory - to engage themselves and be taught with practical theories and applications of music.

It is on this premise that this research was conducted to delve deeper into the meaning of experiences by music teachers handling musically challenged students.

\section{Methodology}

This is qualitative research employing a descriptive-phenomenological research design. This research design helped the researcher to fully describe and understand a lived experience. It emphasizes that only those that have experienced phenomena can communicate them to the outside world (Todres and Holloway, 2004). The experience of the music teachers with the musically challenged students as the phenomenon being described helped the researcher understand the significant parts and essence of their experience. This study has maximized the number of participants depending on the saturation of data. Seven participants have met the criteria who were selected purposively and provided necessary information relative to the study. Moreover, the study was conducted in one of the Higher Education Institutions in Eastern Visayas, Philippines. The researcher has chosen the site for the following reasons: 1) The school offers music education classes to students taking up teacher education program specifically Bachelor of Physical Education and Bachelor of Elementary Education; 2) The researcher has the access to the data needed. Key informant interview was utilized to draw pertinent data and focus group discussions to the participants to substantiate and supplement the data gathered. The researcher himself is the main instrument in the conduct of this study. Bracketing on the part of the researcher was observed to make sure relevant information from the participants emerged in the study. Three steps were followed in the data analysis (Sundler et. al., 2019).: 1. Achieve familiarity with data through openminded reading; 2. Search for meaning and themes; 3. Organize themes into a meaningful wholeness. 


\section{Results and Discussion}

People are made up of experience from which our disposition, mindset, and viewpoints spring. Musically challenged students were perceived by the teachers based on their experience and prior encounter with the phenomenon. The lived experience of the teachers, meditative and unbiased of their nuances, their personal contexts, preferential teaching approaches and challenges are discussed with the corresponding turning points. These were identified following the interview conducted with seven purposely selected informants from the locale.

\subsection{The Ideal Music Teacher}

According to the informants, certain beneficial characteristics in a teacher help in creating a common ground for the teachers' instruction to build a bridge for the learners' benefit. Likewise, success and effective instruction can often be attributed on the teachers' traits. By becoming a keen evaluator, motivator, understanding, knowledgeable, consistent, flexible, and being a dedicated music teacher, learners become motivated and aware of their responsibility - which is to learn. In the study of Pozo-Munoz et. Al. (2000), taking consideration of the significance of specific values that help learners assess their own teachers, findings suggest that getting the perception of learners toward their teachers about the quality of teaching is possibility. Knowing what the ideal is, based on the conclusions of this study, will help in any instance of designing and developing programs which will improve the quality of teachers possessing attributes for an effective teaching.

\subsection{Challenges in Teaching Musically Challenged Students}

Interest as a primary factor in learning - a fact that the participants identified as one of their main concerns - generalizes the whole learning experience as one of the central factors that dictate the route of a learning journey. Interest in the context of learning is a significant knowledge and behavioral motivation moving component to guide the attention span and facilitate schooling in the process of various contexts (Renninger \& Hidi, 2011). Participants of this study understand interest as a fuel that drives the students to move for learning; hence, it is not directly related to achievement outcomes (Van Yperen, 2003). Interest in learning is a specific relevant component in learning to grasp good music performance and understand different music abilities to help learners not distance themselves from music. In the study of Hidi and Ainley (2009) emphasizes: "Whereas the potential for interest resides in the person, the content and the environment may determine the direction of interest and contribute to its development". Therefore, conducting a study on the effectiveness of interest in learning further encouraged to support the findings of the current study undertaken.

Musical exposure is deemed privilege by many. One can never blame the learner's previous experiences that define the current situation - a present undertaking that the music teachers encountered due to a myriad of reasons. According to the results, even though most of the learners can be very good in some music related tasks considering practice and time, a small number of them just can't perform the same musical experience as others do, which was the case of the music teachers. Clear associations on implicit learning describe the whole experience. Implicit learning is a main factor for the acquisition of a complex, systematic, established environment from mere interaction, such as musical skill acquisition (Rohrmeier \& Rebuschat, 2012).

Differing level of musical ability simply implies distinctive musical aptitude among learners. This study has found that individual differences played a significant role in this aspect that made a handful of students with innate musical abilities and innumerable learners who can account music the same with others be observed in most classes. The music teachers reconciled the conflicting patterns and ideas relative to the differing amount of competence and skill that is put in place by the learners. Shreds of evidence could never deny the authenticity of these claims how differing musical ability sets the bar for individual differences in the classroom. The work of 
Davidson (2017) also shows that there is no relationship between competence in rhythmic expression and knowledge in music that can be translated in singing. In common terms, identifying music patterns quickly is just a skill of some in carrying out sound identification patterns compared to others. As O'neal (2012) defined it, musical ability in its context would mean a generality of abilities to conceive and understand structures in music that is absent or present in changing degrees.

Time meddling with the situation seems problematic for the teachers. Accompanied with so many topics to be accommodated in a semester, it has become a learning issue for the teachers dealing with a solution. Devoting time in any endeavor surely pays off; hence, decongesting learning experience would mean less gain and would hamper the opportunity of the learners for a quality instruction; which was the case of the music teachers. As cited in the work of Serrano (2011), in cognitive psychology, several researchers have studied the impact of distribution of time on learning. Most results of study conducted have understood that factors that are presented in spaced dimensions, with time or other intervening items between the presentations of the target forms, are better remembered and learned than the material in massed presentations.

Lack of facilities and equipment is nothing new when the issue is centered on learning instruction. This problem among the music teachers arose when the class size in the classroom was not justified according to the number of resources that can accommodate learners. According to Owoeye (2011), the facilities of a school is conforming as an experience changing component in interactive learning. All benefits of learning and teaching of the conditions on sufficient equipment and instructional facilities in learning cannot be over-emphasized. Clearly, even teaching in a State University, based on the teachers' experiences, the school's equipment cannot still suffice the needs of the learners. Efficiency and high productivity are greatly influenced in the relevance, availability, and adequacy (Oni, 2013).

\subsection{Positive Regard Towards Teaching Musically Challenged Students}

Personal sentiments extracted from the participants altered the process. It has accentuated how complicated the phenomenon is and the situation that the other teachers are in; suggesting how complex teaching is. Most of the teachers expressed how fulfilling it is to make this challenge as an achievement by changing the lives of the learners while others see them opposite - justifications on their current struggles: attitude, sense of idealism, negative perception towards teaching, difficulty in teaching and being an out-of-field teacher. Nevertheless, the teachers have reassured that they are above the phenomenon and would do however they can help the learners. According to Fives and Buehl (2010), teaching translates to 'whatever it takes' to aid learners understand patterns, concept, and systems. It is to be well-informed about: instruction, method, curriculum, and using that information to pave the way for students to become inquisitive and active members of learning communities.

Attitude, values, needs and interest are the main foci constituting the personality of the music teachers. Embracing the situation and spreading positivity was another solution for the teachers. Their profession itself speaks about compassion for their learners. They have believed that whatever the status of the learner is, they are still predisposed to make the learners be susceptible to all the opportunities in learning; that learners are capable of learning and can manage to optimize their skills and talents, making the instruction more inclusive and diversified. As cited by Bektas and Nalcaci (2012), the teacher is the most important part of an education system, because the impact of the teachers on the educational programs and students is known to be much superior to any other factors.

\subsection{Opportunities in Teaching Musically Challenged Students}

Making the learners believe in themselves open doors for their confidence and motivation. By genuinely guiding them to their true potentials and emphasizing their strengths rather than their 
weaknesses, they will start developing self-confidence, which they will need while immersing in a new challenge. In the words of Kim and Pekrun (2014), emotions and motivation portray a significant role in performance and learning. Furthermore, curriculum developers and research enthusiasts are sometimes not heeding too much on this issue due to its indirect impact on the students' learning and performance.

Verifying someone's theory in practice is a found opportunity by the music teachers. Attending seminars and workshops was found of great importance - to apply and re-echo the substance learned to the challenged learners. Theories and practical lessons employed are given an avenue to be proven if suited to the needs of the learners.

From a mere standpoint of a teacher teaching musically challenged students, the experience itself is fulfilling. For the teachers, learning through experience is gained through subsequent effort; that with time, they could get the understand the phenomenon being studied and through experience as well, they could deal with the problem efficiently. As cited by Fatahi (2019), the most relevant of these spirals were a persisting exploration into the naturality of experience and the process of learning from it. With this idea of experiential learning, it is directly emphasized on experience and several contexts which is used as a primary source of learning.

\subsection{Best Practices in Teaching Musically Challenged Students}

Innovative strategies were the solution found by the teachers in dealing with musically challenged students. These could either go with existing musical or educational strategies such as the Kodaly method (Penny, 2012), student-centered learning (Wright, 2011), cooperative learning (Millis, 2010), and inclusive approach in learning wherein students are not discriminated based on their level of competency. Personal strategies were also found effective by the teachers in addressing the need of the learners; strategies such as informal instructions to inject humor in lessons and light discussions, the use of voice and instruments as supplement to enrich the discussions, personal gimmicks in teaching, consistent repetitive exercises, and musical games. Evidence-based practice in teaching is imperative in settings with this phenomenon because it bridges the gap between research findings and practice. Promoting student interest and enthusiasm for learning is therefore crucial when teaching musically challenged learners. In the work of Tuckman and Kennedy (2011), innovative amendments must be administered to not stretch the gap for success in learning, specifically, learners' lack of interest and significant learning strategies.

Rewards are found gratifying for the students in a form of appreciation and incentives to boost their willingness to be engaged in the process. The teachers made it possible to implement positive reinforcements that would manage student's behavior and to create a thought of the modification of behavior as a method that works in encouraging students and in teaching. According to Diedrich (2010), one factor of educating is the teachers' skills to address their learners' demeanor. A lot of teacher training programs in education uncover pre-service education to several techniques for student management in terms of attitude since one of the challenges in educating continues to be discipline and management in the classroom. Less number of teachers believe that it is not their job and line of work to provide positive reinforcement; their feeling is towards the responsibility of the immediate parents of the learners. Studies in the field of behavioral skills training suggests that communication as a form of feedback and positive reinforcement is greatly significant in improving the behaviors, personalities, and expectations of the learners (Miltenberger, 2008).

The advent of technology was a great boon to the academic sector. In this aspect, it has provided the teachers a chance to augment the level of their instruction to cope with the needs of the musically challenged learners. Tasks that can be completed way easier and faster than the traditional manner. Computer software were used as programmed instructions to aid the learners in their struggle for academic answers. Research in the recent years describe that for integration of technology to be fully approved as part of the learning process, the educator has an important role in the process of assimilation and to aid in creating an interactive learning experience which would 
let technology grow and plant its own roots as part of the indispensable tool of education (e.g., Arrowood et al., 2010; Ertmer et al., 2012; Vannatta \& Banister, 2009).

Patience is a virtue. Among all the responses to deal with the phenomenon, patience is still the best solution for the problem; that whatever the challenge is, temper shouldn't be involved but patience instead. Devoting time and effort is needed by the musically challenged students to progress in their endeavor. "Patience" is, of course, an act of being patient: to bear a trial so calm with no complaints; to manifest endurance even being provoked or strained; to not being in a rush; to show being steadfast despite oppositions, difficulties, or adversities (Hirsch, 2014).

General Essence: The success of the learning process in teaching musically challenged students is clearly dependent on the issues of interest, support, facilities and equipment, and most especially, the quality of teachers handling musically challenged students who innovate strategies and are willing to accommodate the learners; thus, to deal with the phenomenon, music and its related elements should be appraised as a major subject where all components will be truly demonstrated with devoted teachers employing innovative strategies with integration of technology to allow learners to find out the values immanently to make them motivated and confident in the subject.

\section{Conclusions}

Understanding the teachers' experience of the phenomenon is essential to the development of the essence of their experience and answers to a lot of academic queries; specifically, in music. Under these circumstances, a coherent plan of action must be enforced by the teachers since aversion towards learning music education is apparent in the process thereby affecting the likelihood of student's interest to immerse in the subject. According to the study, promoted interest in learning as applied in the classroom increases the intrinsic motivation of the learners and other means of doing so (Rotgans \& Schmidt, 2011). It also reveals that poor musical background is considered the thought-out culprit of the phenomenon which then later emerges to the differing level of musical ability among the learners; hence, based on the study, there is establishment of a clear association between musical exposure and the musical ability of the learners (Whidden, 2010). Patience have been found of great function in dealing with the phenomenon which has a significant relationship to the attitude of the teachers towards the students. Teacher's behavior towards the phenomenon is seen as dependent on their personality and skills. Consequently, years of experience in teaching music is capacitating the teachers to be patient and be equipped with strategies and techniques necessary to address the needs of the students. The school institution has a major role in building up a good musical foundation by supporting the needs of the learners and augmenting the quality of instruction delivered by the teachers by providing them with essential facilities and equipment. Moreover, the success of the learning process in teaching musically challenged students is clearly dependent on the issues of interest, facilities and equipment, and the quality of teachers handling who are willing to accommodate the learners. Anent to this, if only music is appraised as a major subject where all components will be truly demonstrated with devoted teachers employing innovative strategies with integration of technology to allow learners to find out the values immanently to make them motivated and confident in the subject.

\section{Recommendations}

The interpretation and analysis of the data in the previous chapter revealed that teachers have a massive impact towards the phenomenon. The teachers in music of the formative level should account young learners in their musicality and relevant variables of attitude in determining learners who are low on esteem about their musicality to lessen the occurrence of the phenomenon. Formative years are considered backbone and a strong foundation in the development of learners. 
Grade school teachers should perhaps cater tasks of opportunities so that learners improve their musicality and perceptions of music. Music teachers must be knowledgeable on how the interaction and connection with the musically challenged learners could either hinder or help the developing positive self-concept of the learner. In terms of accurate singing, music teachers must develop this skill on the learners at a very young age. Providing more music related opportunities is relevant for the students' satisfaction and be able to practice over time. However, there have been narrations and accounts from people who self-identify as tone deaf suggesting that music teachers are one of the thought-out culprits in their development; therefore, music teachers who are non-singers should resort to the use of musical instruments as basis for accurate tones (Abril, 2007; Whidden, 2010).

Home environments should foster adaptable musical atmosphere that students may develop musicality at an early age; uncompromising future music-related activities of the child. Parents play a very important character in introducing music to the learners. They should play as support mechanism to the learner that in as much as possible they should provide them all their needs to make a strong musical foundation as the learner progresses.

Government and educational institutions at all levels should train more teachers in music with positive attitude towards the phenomenon to better equip and capacitate them with pedagogical and methodological approaches necessary to address the needs of the students; and provide necessary facilities and equipment to promote conduciveness of the teaching and learning process.

Research in the future should investigate both when and how student's musicality is formed specifically in the formative years and the relationship of the nature of this development to both home and school environment. Are certain grade school music songs and tasks more effective to training and developing singing skills and musicality without compromising the learners' musical self-concept?

\section{References}

Abril, C. R. (2007). I have a voice, but I just can't sing: A narrative investigation of singing and social anxiety. Music Education Research, 9, 1-15. doi:10.1080/14613800601127494.

Arrowood, D., Davis, R. A., Semingson, P., \& Maldonado, M. (2010). Supporting preservice teachers as they use technology to teach children. In Society for Information Technology \& Teacher Education International Conference (Vol. 2010, 1, 2138-2142).

Bektas, F., \& Nalcaci, A. (2012). The Relationship between Personal Values and Attitude towards Teaching Profession. Educational Sciences: Theory and Practice, 12(2), 1244-1248.

Davidson, J. (Ed.). (2017). The music practitioner: Research for the music performer, teacher and listener. Routledge.

de Bruin, L. R. (2018). Evolving regulatory processes used by students and experts in the acquiring of improvisational skills: A qualitative study. Journal of Research in Music Education, 65(4), 483-507.

Diedrich, J. L. (2010). Motivating students using positive reinforcement (Doctoral dissertation).

Ertmer, P. A., Ottenbreit-Leftwich, A. T., Sadik, O., Sendurur, E., \& Sendurur, P. (2012). Teacher beliefs and technology integration practices: A critical relationship. Computers \& Education, 59(2), 423-435.

Fatahi, S. (2019). An experimental study on an adaptive e-learning environment based on learner's personality and emotion. Education and Information Technologies, 24(4), 2225-2241.

Fives, H., \& Buehl, M. M. (2010). Teachers' articulation of beliefs about teaching knowledge: Conceptualizing a belief framework.

Gardner, H. (2011). Frames of mind: The theory of multiple intelligences. Hachette UK.

Hidi, S., \& Ainley, M. (2008). Interest and self-regulation: Relationships between two variables that influence learning.

Hirsch, M. (2014). In pursuit of a wild patience. In The Educational Forum (Vol. 78, No. 4, pp. 402-408). Routledge.

Jacinto, G. (2019). Music Education in the Philippines: Examining the Transition to the K to 12 Curriculum. 音楽文化教育 学研究紀要, (31), 125-134

Kim, C., \& Pekrun, R. (2014). Emotions and motivation in learning and performance. Handbook of research on educational communications and technology, 65-75.

Millis, B. J. (2010). Cooperative learning in higher education.

Miltenberger, R. G. (2008). Teaching safety skills to children: Prevention of firearm injury as an exemplar of best practice in assessment, training, and generalization of safety skills. Behavior Analysis in Practice, 1(1), 30-36.

O’Neill, S. A. (2012). Becoming a music learner: Towards a theory of transformative music engagement. The Oxford handbook of music education, 1, 163-186.

Oni, S. (2013). Challenges and prospects in African education systems. Trafford Publishing. 
Owoeye, J. S., \& Olatunde Yara, P. (2011). School facilities and academic achievement of secondary school agricultural science in Ekiti State, Nigeria. Asian social science, 7(7), 64-74.

Penny, L. L. (2012). The Kodaly method and tonal harmony: An issue of post-secondary pedagogical compatibility. University of Ottawa (Canada).

Pozo-Munoz, C., Rebolloso-Pacheco, E., \& Fernandez-Ramirez, B. (2000). The'Ideal Teacher'. Implications for student evaluation of teacher effectiveness. Assessment \& Evaluation in Higher Education, 25(3), 253-263.

Renninger, K. A., \& Hidi, S. (2011). Revisiting the conceptualization, measurement, and generation of interest. Educational psychologist, 46(3), 168-184.

Rohrmeier, M., \& Rebuschat, P. (2012). Implicit learning and acquisition of music. Topics in cognitive science, 4(4), 525553.

Rotgans, J. I., \& Schmidt, H. G. (2011). Situational interest and academic achievement in the active-learning classroom. Learning and Instruction, 21(1), 58-67.

Serrano, R. (2011). The time factor in EFL classroom practice. Language Learning, 61(1), 117-145.

Sundler, A. J., Lindberg, E., Nilsson, C., \& Palmér, L. (2019). Qualitative thematic analysis based on descriptive phenomenology. Nursing open, 6(3), 733-739.

Temmerman, N. (2005). Children's participation in music: connecting the cultural contexts-an Australian perspective. British Journal of Music Education, 22(2), 113-123.

Todres L, Holloway I (2004) Descriptive phenomenology: life world as evidence. In: Rapport F ed. New Qualitative Methodologies in Health \& Social Care Research. Routledge, London: 79-98

Tuckman, B. W., \& Kennedy, G. J. (2011). Teaching learning strategies to increase success of first-term college students. The Journal of Experimental Education, 79(4), 478-504.

Vannatta, R., \& Banister, S. (2009). Validating a measure of teacher technology integration. In Society for Information Technology \& Teacher Education International Conference (Vol. 2009, No. 1,pp. 1134-1140).

Van Yperen, N. W. (2003). Task interest and actual performance: the moderating effects of assigned and adopted purpose goals. Journal of personality and social psychology, 85(6), 1006.

Whidden, C. O. L. L. E. E. N. (2010). Understanding social-cultural influences affecting non-participation in singing. Multidisciplinary Research in the Arts: e-journal, 2(1), 1-15.

Wright, G. B. (2011). Student-centered learning in higher education. International Journal of Teaching and Learning in Higher Education, 23(1), 92-97. 